the hams to immense smokehouses, other meats to the cellars where they are to be salted, and others to a
place where they are to be cooked and packed in tin cans.

My guide afterward took me into all the different shops of the establishment. I thus saw the porkbutcher's hall, wherein steain machines were hashing meat for the manufacture of sausases. The daily production of this sausage meat is 52,000 pounds. Farther along are manufactured the packages into which lard is put. Here thirty young people were sewing hags, and their duty was so pressing that they scarcely had time to see me pass. They make 8,000 packages per day. Then came the shops where the casks are made for packing salt meats. Then there are the kitchens, which are admirable for their cleanness. Here the pots are full of beef, mutton, and pork, which is afterward canned. Small, revolving, ingenious, and delicate machines close the cans and do the hermetical soldering that promits of the preservation of the meat indefinitely afw the expulsion of the air. In the rooms, too, where the cans are painted and varnished, the women have to work with activity, and they finish from 35,000 to 40,000 per day.

The beeves do not have their throats cut as do the hogs and sheep. Frow the provisional pen in which they are placed they are made to walk one by one through a narrow plank passageway. A trap opens, and the animal, goaded by a man standing on a stage outside, enters a compirtment in which there is room for but himself.

A skillful marksman, standing upon a stage, aims at the forehead, between the eyes, and with the muzzle pretty close. the muzzle pretty close. dead; a second trap is opened, and the victim is dragged to the butchery. From 800 to 900 beeves ar killed thus during the day. As for sheep, only about two hundred per day are slaughtered, and these un dergo the same treatment dergo the same treatment
as the hogs. Annexed to as the hogs. Annexed to the establishment there are the skins of these animals are dressed.

In thes e remarkable abattoirs 3,200 men are employed in summer, and 4,500 in winter ; and more than a hundred horses ar constantly at work in the various departments. The Armour establishment occupies an area of twentyfour acres. In addition to the large shipments of preserved meats that are daily made to all the States of the Union, meat is sold at retail in a store on the ground floor, organized for the convenience of the inhabitants of the city, who habitants of the city, who

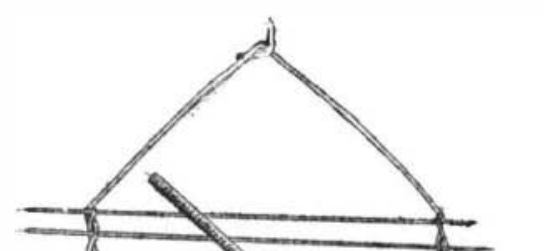

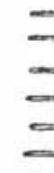

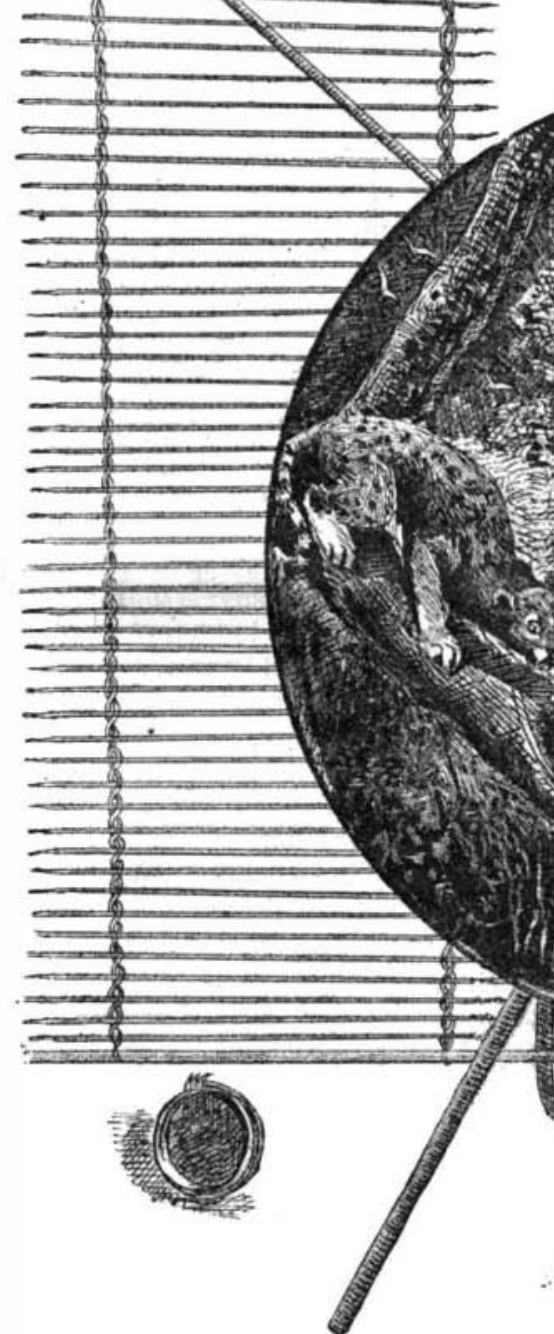

THE ZaRabataNA, OR GUIANa BLOW GUN.

one finds himself in long streets skirted by planks their lost strength by exercising in any way that they piled one upon another, and forming walls 30 or 50 feet prefer. The idea of this aquatic structure appeared in height. Instead of placing the planks in such a way to me to be an original one. It was a great success as to form vertical walls, the lumbermen lay them in last year, and the pale faces of the babies seemed to be overhanging courses. - Owing to this, the rain can wet regaining their fresh colors on this promenade.-A. Tisonly the top planks, which are quickly dried by the sandier, in La Nature.

wind, and the water drips into the middle of the avenues instead of running down along the wood. On this account, dampness has less action upon the planks located near the earth. 'The avenues multiply in all walls. One seems to be in a fantastic eity, whose
vall walls. One seems to be in a fantastic ity, whose
houses have neither doors nor wiudows; while the greeable odor of the pine wood revivifies him.

From an artistic point of view, Chicago offers really nothing of interest. It has a few monuments, but the nly merit of these is their size, and one could not gaze ing, and are very gay- on Sunday, when the inhabitants come to pass a portion of the day in them. In the artificial rivers and lakes there is a continuous moving about of boats of all sorts. One often sees a
frail rowboat filled with young girls of from twelve to markable result of savage ingenuity and skill in the

\title{
THE ZARABATANA OF THE MACOUSHIES
}

Almost the first exercise of ingenuity and skill by the sivage is in the formation of a missile weapon suitable to his peculiar needs. Hence it is we see such a variety of bizarre yet effective weapons in use among. the savage tribes of the world. Where the conditions are right, a sinooth stone projected from the hand may suffice; but the places are very few where the kind of stones, game, and surroundings harmonize so yell that no further effort of ingenuity is needed. The rule is that many difficulties must be overcome before a weapon is produced which fits the needs of the man whose very life is at stake.

It has ben said that the boomerng is the most remaking of a missile weapon; but it seems to in the nt must yield first place to the zarabatana, or blow gun, of the Macoushie Indians of Guiana. The zarabatana and its several accompaniments w a k e a series absolutely unique, in that they so clearly portray the efforts successfully made to overcome a number of seemingly insur mountable obstacles.

Being at once the wettest and warmest portion of the globe, Guiana is char acterized by a vegetation so rank as to defy the utmost efforts even of civilized man to control it. Ordinary missiles are of little use in its tangled for ests, for scarcely an anima fit for food lives elsewhere than among the branches of the lofty trees. Even the large animals, as the jaguar and puma, lurk in the trees, and are not only wounded with diffculty, but if wounded can easily drag themselves away to some leafy covert there to die or, perhaps, recover undiscovered. The missile needed is one that is silent and instantly fatal, no matter what the animal or where it is struck. A vitad part can seldom be chosen by the markeman, or hiding afforded by the dense foliage, consequentl y the missile must be fatal though it only puncture though it only puncture
the flesh. This, of course, involves the use of poison but of such a poison as will be harmless when eaten.

The steps by which the Macoushie accomplished purchases. The establishment sells more than 600,000 in the gardens, and is much more in fashion here than his blow gun, with its instantly fatal poison, are, of hams per year, in addition to the canned meats. From in France. the information that I received, it would appear that Gardeners indulge in the most whimsical eccentrici- course, unknown,

the Chicago abattoir, collectively, export more than ties. The people flocked to South Park; among others, $2,500,000$ per annum.

It will be $s$ en that the meat trade of this city is immense. The trade in lumber is just as extensive. There are immense yards situated on the shores of Lake Michigan, near the mouth of the Chicago River. There are more than three hundred houses engaged in this business, and these own 150 yards, in which a large force of lumbermen is employed. The fire that destroyed a portion of the city in 1871 ruined many capitalists, but none of them became discouraged.

The sawmills of the neighboring cities of Michigan and 11 inois received orders for the material necessary for the building of the destroyed city, and worked day and night. The ruined individuals set themselves to work again, Chicago rose from her ashes as if by enchantment, and the lumber trade for this reason received an extraordinary impetus. In 1877 there were delivered to the yards more than $1,180,000,000$ feet of planks and other timber, and more than $650,000,000$ feet were shipped by rail or boat. This trade is in creasing in extent, and the circulation of the capital employed exceeds that of all the banks of Chicago, and
even that created by the traffic of the grain elevators. to see a large elephant, a cainel, a butterfly, and the American flag formed of matted plants and flowers of various colors planted upon the preensward The up of two tubes, one within the other, the object of the preat attraction was a large sun dial made entirely of inner tube being to supply as nearly perfect a cylinder plants, the hours being formed on the grass with plants as may be, and that is found in a comparatively frail having red leaves. This dial had been well oriented aquatic reed called ourah. The outer tube is made of by the gardener, and the shadow given indicated the the stem of a young palm tree of the genus Ireartea, aour of the day quite accurately.

These public gardens of Chicago would somewhat resemble our Bois du Boulogne, as they are laid out in the same way, were it not that South Park and Lin coln Park, ornamented with artificial lakes and rivers, are upon the banks of Lake Michigan. Hence a comparison becomes impossible. - Lake Miehigan is immense; its opposite shores cannot be seen, so great is
its width. Numerous steam and pleasure boats ply upon it, and one might imagine himself at the seaside. Through the instrumentality of the Floating Hospital Society, there has been constructed in the lake, at weight. They are not larger than a knitting needle Lincoln Park, a jetty two or three hundred yards in and are bound at the base with a tuft of cotton prolength, provided with porticoes, where sick children cured from the tree Bombax ceiba. This makes the may indulge in various gynınastic amusements. Here,
accompanied by their mothers, they can breathe the
rectness and strength of flight. The arrow is pointed A walk in the lumber yards is very interesting. Here, pure air from the waters of Lake Michigan, and regain by drawing it between the teeth of the pirai fish, one 
half of whose lower jaw forms a necessary part of the Macoushie's outfit.

The weapon is now complete, but would be almost harmless without the famous poison, the manufacture th of which is lield a secret among the conjurors of the th

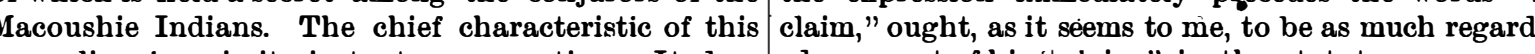
wourali poison is its instantaneous action. It does ed as a part of his "claim," in the statutory sense, as
not kill instantly, but it seems to paralyze first, and
the words that follow, because otherwise the intent then cause death slowly and painlessly. The conse- both of the statute and of the inventor would be quence is to very spot on which it was struck. The composition of the poison as given by Waterton is peculiar. Some of the ingredients he could not learn, but the most important is the wourali vine (Strychnos toxifera). Two or three other plants are used, among them red pepper and hyarri, the latter belonging to the genus Lonotocarpus, and being used to kill fish by throwing into the water. Besides these vegetable ingredients, the fangs of two kinds of serpents are used, and also the bodies of two kinds of ants. The probabilities are, however, that the animal ingredients are unimportant. The materials are all boiled together over a slow fire until the poison in the form of a thick sirup is pro. duced. Dampness is fatal to the poison, so that the utmost care is taken to keep it dry. The wourali is so precious that with it the Macoushie can purchase anything, and among all the neighboring tribes it is used as money.

The arrows, after being sharpened and dipped in the poison, would be extremely dangerous if not carried with peculiar care, and the Macoushie, therefore, has contrived a way at once simple and safe. The arrows are woven into a sort of ribbon on two sets of parallel cords, the points all directed one way. A wheel is then fastened to the end of a shaft tied to the ends of the cords, and the whole ribbon of about five hundred arrows is rolled up, the poisoned tips being kept harmless by resting against the wheel. The whole is then, placed in a water-tight quiver, made of reeds lined kurumanni wax. The cover is made from the hide of the tapir or peccary.

The whole outfit of the Macoushie is so light that when he goes on an expedition he can literally take up his bed and accouterments, and go about as untrammeled as any savage could wish. His hammock he folds around his body, clothing by day, bed by night. Quiver and cotton basket slung over the shoulder, and zarabatana in hand, he is ready for whatever may come.

\section{DECISIONS RELATING TO PATENTS.}

U. So circult Courto-Southern Distet of New York

LA RUE $v$. WESTERN ELECTRIC COMPANY.

PATENT TELEGRAPH INSTRUMENT.

Brown, J.

Lētters patent No. 270,767, granted to Edgar A. Edwards, January 16, 1883, for an improvement in telegraph transmitters, adjudged valid, and the thi claim thereof to have been infringed by defendant.

The invention in controversy consisted in substituting for the trunnionsorpivotsof the lever of telegraph transuitters a torsional spring or strip of metal. The defendant used this torsional spring upon a "sounder." A transmitter is operated by the finger at one end of the line, and a "sounder" is operated by electricity at the other end of the line. The third claim covered the combination, in a telegraph key, of the lever, its torsional spring, and adjusting screws. It was stated in the specification, immediately before the claims, that the invention was not limited to the application of torsional springs to telegraph keys, but they might replace the trunnions of the relay and sounder.

The third claim covers the operative combination, whether in a telegraph key or in a sounder, and the language in the claim, "in a telegraph key," must be taken in connection with the statement in the specifi-

cation that the invention is not limit
torsional springs in telegraph keys.

The statute requirement as to claims in a patent is complied with when the specification shows clearly what the inventor intended to cover in language foun in immediate connection with the claims proper.

Where the combination patented is only a part of

the machine, it is infringed by the

The statute (Rev. St., sec. 4,888) requires that the inventor "shall particularly point out and distinctly claim the part, improvement, or combination which he claims as his in vention or discovery."

Whatever the inventor does clearly point out as his invention, and whatever the application does clearly show that the inventor intends to claim as his, should as it seems to me, be deemed a part of his "claim," when found in immediate connection with the specifications of his claim. There is no arbitrary and formal division of the application into different sections that requires language naturally indicative of the inventor's claim and intention to be excluded from consideration as a part of the claim under the statute, simply plication, or because it does not follow the words

aim," nor is it necessary to use the word "claim." ny language that does clearly and unmistakably inthe inventor intends to secure to himself Pronly wh

U. S. Circuit Court.-Northern District of Illinois. BUTLER et al. v. STECKEL et al.

Blodgett, PATENT BRETZEL CUTTER.

The Butler, Earhart, and Crawford bretzel cutte of patentable novelty.

It being old to cut crackers, cookies, and cokes of arious sorts into different shapes-as, for instance, in the shape of animals or of capital B or character \& only mechanical skill was required to change the die o as to make it cut dough in the shape of bretzel, and this, too, notwithstanding the bretzel is somewhat laid upon each other, so as to require some study, ffort, and experiment to make the shape of the die correspond to its external formation. The fact that the mechanic might be compelled to experiment some
what-that is, cat several dies-does not show invenwhat-

The mere fact that others were long wandering by he wrong path is not evidence that it required invention to accomplish what has been done by taking the direct path pursued by these patentees, whose merit was in overcoming the fixed prejudice in favor of hand made goods, rather than in inventing any radically
new process for making the same goods by machinery.
U. S. Circuit Court.-Eastern District of Missouri. DEDERICK $v$. WHITMAN AGRICULTURAL COMPANY.

Treat, J. BALING PRESS PATENT.

A certified copy of a recorded but unacknowledged instrument purporting to be the assignment of a patsuch assignment, and is sufficient proof thereof in the absence of countervailing testimony.

The first claim of letters patent No. 126,394, granted May 7, 1872, to Frank A. Huntington and John F. Carter for an improvement in baling presses, is for the thereto the peculiar construction of the press box, and is not infringed by a combinationinto which such pres ox does not enter.

First claim of letters patent No. 199,052, granted Jan 8,1878, to Albert A. Gehrt for an improv
able hay and cotton presses, is valid.

A substitution of an equivalent for an ingredient combination covered by a patent cannot avert harge of infringement.

Suit for infringement of the first claim of letters patent No. 126,394, for an improvement in baling presses, and the first claim of letters patent No. 199,052, for a improvement in portable hay and cotton presses. Th complainant sues as assignee. The only evidence of fered of the execution of an assignment to him is a cerin the Patent Office, which purports to be a duly exe
cuted assignment. The admission of the copy was objected to by the defendant. The first claim of letter jected to by the defendant. The
patent No. 126,394 is as follows:

1. The combination of the lever or sweep, $H$, with the lever, G, follower, F, and box, $A$ of a baling press when constructed to operate substantially as herein described.

The first claim of letters patent No. 199,052 is as follows:

1. In a portable press, the combination of a horizonand pivoted double cam at the end of tongue or sweep lever of press, substantially as and for the purpose set forth.

DEDERICK $v$. WHITMAN AGRICULTURAL COMPANY.

Treat, J. BALING PRESS PATENT.

The first claim of letters patent No. 170,998, granted P. K. Dederick December 14, 1875, for an improveent in baling presses, is void for want of invention. to $P$. K. Dederick February 10,1880 , for an improve
ment in baling presses, is, in view of the previous state of the art, void, unless restricted to the peculiar device nemed in the copmbination therein described. tified copy of an unacknowledged instrument on record guide frame with a reciprocating follower, pitman

The first claim of letters patent No. 224,281, granted Any perfectly clear expression of what the substantially as described.

ventor intends to secure to himself is virtually a part 2 . The combination of a press box, a bale chamber, the "claim." The reasons for confining the pat- and a reciprocating traverser, and means for increasing nt to the "claim," viz., because the inventor is pre- or diminishing at will the area of the passage between umed to intend to dedicate to the public so much of the press box and the bale chamber, whereby to render
the sections or charges of material larger or smaller Patent Office is presumed to intend to grant the patent 1 and produce bales of greater or less density, substantithe press box, beveling the mouth of the bale chamber

The mere change of position of an old mechanical deame result involves no patentable invention.

Suit for the infringement of the first claim of letter patent No. 170,998 and the first claim of letters patent No. 224,281, both for improvements in baling presses. id claims are respectively as follows ally as described.

U. S. Circuit Court.-District of Massachusetts. LIBBEY $v$. MOUNT WASHINGTON GLASS COMPANY $e t$ al.

Colt, J. GLASSWARE PATENT

On motion for preliminary irijucetion, letters patent No. 282,002, granted to Joseph Locke, July 24, 1883, for an improved article of glassware, and the process of making the same, sustained.

This patent was for an article of glassware of ruby and amber colors made from a gold-ruby compound, which was a well-known glass mixture containing gold. Patentee discovered that by reheating only a portion of the article the ruby color was developed in the reheated portions, while the other portions remained amber color, producing an article known as " amberina." This process of obtaining party-colored glassware had been before practiced, but not with gold-ruby. compound-the amber color had not been obtained, except by accident, and then with no thought of utilizing the product; and, although this fact undoubtedly led patentee to make the discovery, the patent was sustained. The specification of this patent sufficiently describes the invention to enable persons skilled in the art to which it relates to produce the patented article.

A disclaimer can be made after the suit is commenced; and the defendants in this case having knowledge of their defense to a motion for an injunction, held that their rights had not been prejudiced in any degree by the disclaimer.

The American Humane Association presents the following suggestions relative to the care of animals during the heated term :

Provide water-fresh, pure water. Think, reader, how you are refreshed by a drink of cool water on a hot day. The lower animal

The active dog requires drink frequently during the hot day, as does also the cat ; and a dish of fresh water hould stand where they can have access to it. Un doubtedly many a dog is driven to madness through lack of water ; and the testimony is that hydrophobia is almost unknown in

Every city, village, and country town should be liberally supplied with drinking fountains for animals, and they should be so constructed that even the smallest dogs can drink from them. No gift to a people confers a greater pleasure than a fountain, and that person who turns aside a stream from the field and gives a atering trough to the roadside, or provides a fountain which man and bear

Give the horse frequent opportunity to quench thirst t times when not too much overheated, and before eating. To drink freely immediately after eating prevents a favorable digestion of food

Provide shade. How instinctively we seek the shadow when the sun is pouring its hot rays on the dry and parching earth! If thepastureis not provided with shade trees, in a convenient locality set four, six or eight supports, across which place straw or grass, and thus, in a brief time and with little labor, make a shade in which animals can rest from the heat of the sun, to the great comfort of themselves and benefit to their

Remove the harness from the horses in the hot day whenever you desire to give them a full, free rest, and once during the day, preferably at night, a thorough currying and grooming will not only give rest, but will do about as much toward improving the animal's condition as will the oats.

Examine the harness on your working team, end you will discover that blinds, check reins, and cruppers are simply torturing contrivances, serving no useful purpose. Take them all off for the convenience of yourselves and the comfort of the horses. Keep the stable well ventilated and free from the strong ammonia which is injurious to the eyes. Assist the animals to protect themselves against flies, feed regularly, hitch in the shade, and remember that the care which wil give comfort to the lower animals will make them
doubly profitable to their owners, aside from the hu. mane bearing upon the subject. 